\title{
Iliotibial Band
}

National Cancer Institute

\section{Source}

National Cancer Institute. Iliotibial Band. NCI Thesaurus. Code C139207.

A dense band of avascular, regular connective tissue, it is formed as the union of the superficial and deep layers of the tensor fascia latae, creating a thick band that extends inferiorly, taking its origins from the iliac crest, the tensor fascia latae, and the gluteus maximus, travelling inferiolaterally along the thigh, and inserting on Gerdy's tubercle on the lateral aspect of the tibia. Functionally, the iliotibial band helps to flex, abduct, and medially rotate the femur at the hip joint, and it also helps to stabilize the knee laterally. 